ISSN (e)-2347-176x ISSN (p) 2455-0450

crossref DOI: https://dx.doi.org/10.18535/jmscr/v7i6.107

\title{
Prevalence of Non-Adherence to Treatment among Patients of Bipolar Affective
} Disorder

\author{
Authors
}

\section{Rameshwar S Manhas ${ }^{1}$, Gaurav S Manhas ${ }^{2 *}$, Angli Manhas ${ }^{3}$, Rishabh Sharma ${ }^{4}$, Jagdish R Thappa ${ }^{5}$, Rukhsana Akhter ${ }^{6}$ \\ ${ }^{1}$ Senior Resident, Department of Psychiatry, Government Medical College, Jammu, J\&K, India}

${ }^{2}$ Resident Scholar, Department of Radiodiagnosis, Government Medical College Jammu, J\&K, India

${ }^{3}$ Senior Resident, Department of Ophthalmology, Government Medical College Jammu, J\&K, India

${ }^{4}$ Resident MBBS, Government Medical College Jammu, J\&K, India

${ }^{5}$ Prof \& HOD, Department of Psychiatry, Government Medical College, Jammu, J\&K, India

${ }^{6} \mathrm{MA}$ in Psychology, Intern, Department of Psychiatry, Government Medical College, Jammu, J\&K, India

*Corresponding Author

Dr Gaurav S Manhas MBBS,MD

R\O : 381-A Indira Colony, Timber Road, Janipur, Jammu, J\&K, India

\begin{abstract}
Background: Management of bipolar disorder include acute management aimed at reducing acute symptoms and maintenance management aimed to reduce the possibility of relapse and to reduce the risk of suicide by addressing incomplete remission, quality of life and functional impairment. Adherence to medication is a problem in bipolar disorder which contributes substantially to efficacy effectiveness gap and the burden of morbidity and mortality of the illness.
\end{abstract}

Aims: To find prevalence of non adherence to treatment in patients of bipolar affective disorder.

Materials \& Methods: This is a cross-sectional study which was conducted on patients with bipolar affective disorder attending the outpatient department (OPD) of Government Psychiatric Diseases Hospital, Jammu. After meeting inclusion and exclusion criteria, total of 109 patients were selected for the study. Various parameters like age, sex, education, marital status etc were collected. A patient is said to be non adherent to treatment if skips more 3 doses in month and adherent if skips less 3 doses in a month.

Results: Prevalence of non adherence to treatment among the bipolar patients was 59.6\%. About $76.5 \%$ patients below 20 years of age, $61.8 \%$ males, $65.8 \%$ from rural areas, $75 \%$ uneducated, $76.6 \%$ unemployed and $64.9 \%$ married patients were non adherent to treatment. Patients who had parents as their caretakers had lower rates whereas those belonging to lower socioeconomic class had higher rates of non adherence.

Conclusion: There is high prevalence of non adherence among patients suffering from bipolar affective disorder which may affect the treatment outcome and management of these patients and thus it is suggested that better health education to these patients and their attendants should be given in order to maintain compliance to treatment and prevention of relapses.

Keywords: BPAD, Non Adherence, Prevalence. 


\section{Introduction}

Bipolar disorder is a severe, chronic and cyclic disorder with a life time prevalence of $1.6-1.8 \%$. This illness has pervasive effects in most spheres of life with significant attendant morbidity and mortality. ${ }^{1}$ Suicide rates in bipolar disorder are 12 times higher than the general population which is a clear indication to optimize available therapeutic options, and to develop novel approaches. ${ }^{2}$ Management of bipolar disorder include acute management aimed at reducing acute symptoms and maintenance management aimed to reduce the possibility of relapse and to reduce the risk of suicide by addressing incomplete remission, quality of life and functional impairment. ${ }^{3}$

Adherence to medication is a problem in bipolar disorder which contributes substantially to efficacy effectiveness gap and the burden of morbidity and mortality of the illness. ${ }^{4}$ The complexity of addressing this adherence problem is exacerbated by the multifactorial aetiology of non-adherence as well as by lack of consensus about the definition and assessment of adherence. ${ }^{5,6}$ Everyday clinicians are often confronted with patients with adherence problems while providing clinical treatment to peoples with bipolar disorder but seldom address this risk factor for poor outcomes. ${ }^{7}$

Non-adherence to drug therapy in patients of bipolar affective disorders can cause deleterious effects on patients and their families and improving adherence can produce greater impact on the health of a population than any specific medical treatment by reducing morbidity, mortality and decreasing cost of treatment and health-care system. ${ }^{8}$ Hence this study was conducted to find prevalence of non adherence to treatment in patients of bipolar affective disorders.

\section{Methodology}

This is a cross-sectional study which was conducted on patients with bipolar affective disorder attending the outpatient department (OPD) of Government Psychiatric Diseases Hospital, Jammu. Informed consent was taken prior to start of study. After meeting inclusion and exclusion criteria, total of 109 patients were selected for the study. Various parameters like age, sex, education, marital status etc were collected. A patient is said to be non adherent to treatment if skips more 3 doses in month and adherent if skips less 3 doses in a month. ${ }^{8}$

\section{Inclusion Criteria}

- diagnosed cases of bipolar affective disorder (BPAD)

- patients above 18 years of either sex

- patients who had been receiving treatment for at least 2 months

- those patients/attendants who gave consent.

\section{Exclusion Criteria}

- those suffering from acute mania

- cases of severe bipolar depression with currently suicidal ideation

- those having comorbid medical illness

\section{Statistical analysis}

Analysis of data was done using statistical software MS Excel / SPSS version 17.0 for windows. Data presented as percentage (\%) as discussed appropriate for quantitative and qualitative variables.

\section{Observations and Results}

In the present study, prevalence of non adherence to treatment among the bipolar patients was 59.6\%.

Table 1 shows that $76.5 \%$ patients below 20 years of age, $68.1 \%$ between 21 to 40 years, $39.1 \%$ between 41 to 60 years and $50 \%$ above 60 years of age were not adherent to treatment. $61.8 \%$ males and $56.1 \%$ females were non adherent to treatment. Prevalence of non adherence was more among the patients from rural areas $(65.8 \%)$ than urban areas $(47.2 \%) .75 \%$ uneducated patients and $54.3 \%$ educated patients were non adherent to their treatment. There were $76.6 \%$ unemployed patients and $46.8 \%$ employed patients who were non adherent to their treatment. Majority i.e. $64.9 \%$ married patients were non adherent compared $56.9 \%$ unmarried who were non adherent to treatment. Majority of the patients who 
were non adherent belongs to lower socioeconomic class $(71.5 \%)$ followed by middle socioeconomic class $(48.7 \%)$ and upper class (14.3\%). Patients who had parents as their caretakers have lower rates of non adherence compared to spouses (65.1\%), siblings (77.8\%), and others (80\%).

Table 1 shows prevalence of non adherence to treatment in patients of bipolar affective disorder

\begin{tabular}{|c|c|c|c|}
\hline & Number of patients & Treatment adherent & Treatment non adherent \\
\hline \multicolumn{4}{|c|}{ Age (in years) } \\
\hline Below 20 & 17 & $4(23.5 \%)$ & $13(76.5 \%)$ \\
\hline $21-40$ & 47 & $15(31.9 \%)$ & $32(68.1 \%)$ \\
\hline $41-60$ & 23 & $14(60.9 \%)$ & $9(39.1 \%)$ \\
\hline Above 60 & 22 & $11(50 \%)$ & $11(50 \%)$ \\
\hline \multicolumn{4}{|l|}{ Sex } \\
\hline Male & 68 & $26(38.2 \%)$ & $42(61.8 \%)$ \\
\hline Female & 41 & $18(43.9 \%)$ & $23((56.1 \%)$ \\
\hline \multicolumn{4}{|l|}{ Residence } \\
\hline Rural & 73 & $25(34.2 \%)$ & $48(65.8 \%)$ \\
\hline Urban & 36 & $19(52.8 \%)$ & $17(47.2 \%)$ \\
\hline \multicolumn{4}{|l|}{ Education } \\
\hline Educated & 81 & $37(45.7 \%)$ & $44(54.3 \%)$ \\
\hline Uneducated & 28 & $7(25 \%)$ & $21(75 \%)$ \\
\hline \multicolumn{4}{|c|}{ Employment status } \\
\hline Employed & 62 & $33(53.2 \%)$ & $29(46.8 \%)$ \\
\hline Unemployed & 47 & $11(23.4 \%)$ & $36(76.6 \%)$ \\
\hline \multicolumn{4}{|c|}{ Marital status } \\
\hline Married & 72 & $31(43.1 \%)$ & $41(56.9 \%)$ \\
\hline unmarried & 37 & $19(35.1 \%)$ & $24(64.9 \%)$ \\
\hline \multicolumn{4}{|c|}{ Socio economic class } \\
\hline Upper & 7 & $6(85.7 \%)$ & $1(14.3 \%)$ \\
\hline Middle & 39 & $20(51.3 \%)$ & $19(48.7 \%)$ \\
\hline Lower & 63 & $18(28.6 \%)$ & $45(71.4 \%)$ \\
\hline \multicolumn{4}{|c|}{ Relation of the caretaker } \\
\hline Parents & 52 & $26(50 \%)$ & $26(50 \%)$ \\
\hline Spouses & 43 & $15(34.9 \%)$ & $28(65.1 \%)$ \\
\hline Siblings & 9 & $2(2.2 \%)$ & $7(77.8 \%)$ \\
\hline Others & 5 & $1(20 \%)$ & $4(80 \%)$ \\
\hline Total & 109 & $44(40.4 \%)$ & $65(59.6 \%)$ \\
\hline
\end{tabular}

\section{Discussion}

In the present study, 65 out of 109 patients were non compliant to their medications which shows that prevalence of non adherence to the medications in patients of bipolar affective disorder (BPAD) was 59.6\%. In bipolar affective disorder there are chances of early recurrence of mania if long term prophylactic medication is discontinued. Younger age, past history of non-adherence, fewer episodes of illness, male gender, elevated mood, history of grandiosity and complaints of missing highs were the risk factors associated with non adherence to treatment in case of BPAD patients. ${ }^{6}$ The other contributing factors in the non adherence to treatment were lack of insight, lack of knowledge about the treatment outcome and poor awareness regarding the natural course of disease. ${ }^{8}$ Side effects like sedation, weight gain etc were also associated with poor adherence to treatment. ${ }^{9}$ Our finding is in agreement with Sharma $\mathrm{S}$ et al who found higher prevalence of non adherence in BPAD patients. ${ }^{8}$ Other studies had found that prevalence of non adherence in BPAD patients varies from 20 to $66 \% .^{10-13}$

Majority i.e. $76.5 \%$ patients below 20 years were non adherent to medication followed by $68.1 \%$ 
between 21 to 40 years, $50 \%$ above 60 years and $39.1 \%$ in the age group of 41 to 60 years. Younger patients were more concerned with the initial side effects of the medications, doesn't liked that their euphoric mood being suppressed by medicine and taking medicines regularly may produce a feeling of being a mental patient were most common reasons for non adherence in younger population. ${ }^{6}$ Our finding is in agreement with Berk $\mathrm{M}$ et al who observed that young age is negatively associated with adherence in BPAD patients. ${ }^{14}$ Similarly Keck $\mathrm{PE}$ et al and Goodwin $\mathrm{F}$ et al had also observed that being young has a negative association with treatment adherence. ${ }^{15,16}$ Our finding can be supported by Ritchie CW et al who observed that rates of adherence to medication in psychiatric patients increases with the increase in the age of patients. ${ }^{17}$ Our finding is in contrast to Sharma $S$ et al who observed higher rates of adherence to medication in the younger age group when compared to other age groups ${ }^{8}$ which can be explained Dolder $\mathrm{CR}$ et al who found that age had no significant effect on adherence. ${ }^{18}$

About $61.8 \%$ males and $56.1 \%$ females were non adherent to medications. In the Indian culture majority of the females perform household work and males go for outside work $^{19}$ where they may miss medication due to absence of caretaker. Moreover factors like substance abuse and alcohol dependence were more in Indian males compared to females and these factors were responsible for non adherence. ${ }^{15,20}$ Our finding is in accordance with Sharma $\mathrm{S}$ et al who observed that non adherence to treatment was more in males than females. ${ }^{8}$ Similarly Goodwin F et al and Danion JM et al had observed that male gender is negatively associated with treatment adherence. $^{21,22}$

$65.8 \%$ patients from rural area and $47.2 \%$ patients from urban areas were non adherent to their treatment. Our finding suggests that non adherence was more common in rural patients than patients living in urban areas. Lack of psychiatric medication in rural medical shops and government dispensaries, lack of money for buying medicines and the distance travelled to hospital may be the factors associated with poor compliance to treatment in patients of rural India. ${ }^{8}$

Among uneducated patients $75 \%$ were non adherent to medication whereas in educated ones $45.7 \%$ were non adherent and $54.3 \%$ were adherent to medications. Higher rates of adherence to medication among educated patients may be due to better understanding of disease, importance of medication and consequences of medication discontinuation. Our finding is in accordance with Frank E et al who observed that education is positively associated with increase in adherence rates among BPAD patients. ${ }^{23}$ Similarly Sharma $S$ et al had also observed better adherence among educated patients. ${ }^{8}$ However Lacro JP et al found that education does not affect adherence rate among psychiatric patients. $^{24}$

$76.6 \%$ patients who were unemployed were non adherent to medication as compared to $46.8 \%$ employed patients who were non adherent. Unemployment means no money which decreases the purchasing power of the patient and their families resulting in non adherence to medication. Our finding is in accordance with Sharma $\mathrm{S}$ et al who observed that $66.67 \%$ unemployed patients of psychiatric disorder including BPAD were non adherent to their treatment. ${ }^{8}$

$64.9 \%$ patients who were unmarried were non adherent to their medications whereas $56.9 \%$ married patients were associated with non adherence to medications. Fear of sexual side effects due to medication, negative attitudes to long-term prophylaxis and feeling of being a mental patient by taking medication on long term may be the factors associated with non adherence with medication in unmarried patients. ${ }^{6}$ Our finding is in accordance with Frank E et al who found that marriage is positively associated with adherence to medication whereas being single is negatively associated with 
non adherence. ${ }^{23}$ However our finding is in contrast with Sharma $\mathrm{S}$ et al who found discontinuation of medication was more in married as compared to unmarried patients. ${ }^{8}$ The difference in results of our study and Sharma $\mathrm{S}$ et al can be explained by the fact that factors like marital status does not affect compliance. $^{25}$

In the present study, $71.4 \%$ patients of lower socioeconomic class, $48.7 \%$ patients of middle and $14.3 \%$ of upper socioeconomic class were non adherent to treatment. Patients with lower socioeconomic status were usually illiterate, unemployed, uneducated and poor, all being risk factors for depression and thus increasing the incidence and prevalence of depression. ${ }^{26}$ A patient of lower socioeconomic status when suffers from an episode of mania temporarily overcome his difficult, depressive experience of his past and dislikes to suppress their euphoric mood and hence remain non compliant to medication. ${ }^{6}$

In the present study $50 \%$ patients who had parents as the caretakers were adherent to medications whereas those who had siblings and others as caretakers had high rates of non adherence to medication. The parents of the mentally ill patients were bothered about the health of their child, takes the mental illness seriously. ${ }^{27}$ Parents ensure compliance by supervising the medication intake at home and bring the patients for regular follow ups and treatment. ${ }^{8}$ Our finding is in accordance with Sharma S et who observed rate of non adherence were low in patients who had parents as their caretakers. ${ }^{8}$

\section{Conclusion}

There is high prevalence of non adherence among patients suffering from bipolar affective disorder which may affect the treatment outcome and management of these patients. In addition to this, prevalence of non adherence was high in those patients who were young, males, living in rural areas, unmarried, uneducated, unemployed and were of lower socioeconomic status. So it is suggested that better health education to these patients and their attendants should be given in order to maintain compliance to treatment and prevention of relapses.

\section{Acknowledgement}

Thanks from the core of my heart to GOD and my parents Smt \& Sh. Veena-Joginder Singh for their blessings.

\section{Declaration:}

Funding: No funding sources

Conflict of interest: None declared

\section{References:}

1. Kessler RC et al. Lifetime and 12 month prevalence of DSM-II-R psychiatric disorders in the United Harris States. Results from the national comorbidity study. Arch Gen Psychiatry 1994; 51: 8-19.

2. EC and Barraclough B. Suicide as an outcome for mental disorders: a meta-analysis. Br J Psychiatry 1997; 170: 205-228.

3. Sachs GS and Rush AJ. Response, remission and recovery in bipolar disorders: what are the realistic treatment goals? J Clin Psychiatry 2003; 64: 18-22.

4. Guscott $\mathrm{R}$ and Taylor L. Lithium prophylaxis in recurrent affective illness: efficacy effectiveness and efficiency. $\mathrm{Br} \mathrm{J}$ Psychiatry 1994; 164: 741-746.

5. Sajatovic $\mathrm{M}$ et al. Enhancement of treatment adherence among patients with bipolar disorder. Psychiatr Serv 2004; 55: 264-269.

6. Lingam $\mathrm{R}$ and Scott J. Treatment non-adherence in affective disorders. Acta Psychiatra Scandinavia 2002; 105: 164-172.

7. Scott $J$ and Pope M. Non adherence with mood stabilizers: prevalence and predictors. J Clin Psychiatry 2002; 63:384-390.

8. Sharma $\mathrm{S}$ et al. Prevalence and factors associated with medication compliance in 
Indian patients suffering from mental disorders. Trop Doct 2012:42: 28.

9. Fenton WS, Blyer CR and Heinssen RK. Determinants of medication compliance in schizophrenia: empirical and clinical findings. Schizophr Bull 1997;23:637-651.

10. Scott J. Predicting medication non-adherence in severe affective disorders. Acta Neurolopsychiatr 2000; 12: 128-130.

11. Bech P et al. Lithium maintenance treatment of manic-melancholic patients: its role in the daily routine. Acta Psychiatr Scand 1976; 53: $70-81$.

12. Connelly $\mathrm{CE}$ et al. Adherence to treatment regimen in a lithium carbonate clinic. Arch Gen Psychiatry 1982;39:585-588.

13. Cochran SD. Compliance with lithium regimens in the out-patient treatment of bipolar affective disorders. J Compliance Health Care 1986;1:151-169.

14. Berk $\mathrm{M}$ et al. A collaborative approach to the treatment alliance in bipolar disorder. Bipolar Disorders 2004: 6: 504-518.

15. Keck PE et al. Compliance with maintenance treatment in bipolar disorder. Psychopharmacol Bull 1997; 33: 87-91.

16. Goodwin F et al. Manic Depressive illness. New York: Oxford University Press, 1990.

17. Ritchie CW et al. Predictors of adherence to atypical antipsychotics (risperidone or olanzapine) in older patients with schizophrenia: an open study of $31 / 2$ years duration. Int $\mathrm{J}$ Geriatr Psychiatry 2010;25:411-18.

18. Dolder CR et al. Interventions to improve antipsychotic medication adherence: review of recent literature. J Clin Psychopharmacol 2003;23:389-99.
19. Trivedi JK. Prescription pattern of mood stabilizers for bipolar disorder at a tertiary health care centre in north India. Indian journal of psychiatry 2013;55(2): 131-134.

20. Swartz $M$ et al. Violence and severe mental illness: the e€ects of substance misuse and non-adherence to medication. Am J Psychiatry 1998;155:226-231.

21. Goodwin F, Jamison JK. Manic Depressive illness. New York: Oxford University Press, 1990.

22. Danion JM, Neunrither C, Krieger-Finance $\mathrm{F}$ et al. Compliance with long-term lithium treatment in major affective disorders. Pharmacopsychiatry 1987; 20: 230-231.

23. Frank E, Prien RF, Kupfer DJ, Alberts L. Implication of non-compliance in research in affective disorders. Psychopharmacological. Bulletin 1985; 21: 37-42.

24. Lacro JP, Dunn LB, Dolder CR, Leckband SG, Jeste DV. Prevalence of and risk factors for medication non-adherence in patients with schizophrenia: a comprehensive review of recent literature. J Clin Psychiatry 2002;63:892-909.

25. Buchanan A. A two-year prospective study of treatment compliance in patients with schizophrenia. Psychol Med 1992;22: 787-97.

26. Sadock BJ, Sadock VA. Mood disorders in: Kaplan \& Sadock's Synopsis of Psychiatry: Behavioral Sciences/Clinical Psychiatry. 10th ed. Lippincott Williams \& Wilkins; 2007; Chapter15:527-578.

27. Chadda RK. Caring for the family caregivers of persons with mental illness. Indian Journal of Psychiatry 2014;56(3):221-227. 